\title{
Viabilidade técnica e econômica da aplicação de estrobilurinas em milho
}

\author{
Rodrigo Véras da Costa ${ }^{1}$, Luciano Viana Cota $^{1}$, Dagma Dionísia da Silva ${ }^{1}$, Walter Fernandes Meirelles ${ }^{1}$ \\ \& Fabrício Eustáquio Lanza ${ }^{2}$
}

${ }^{1}$ Embrapa Milho e Sorgo, Cx. Postal 285, 35701-970, Sete Lagoas, MG, Brasil; ${ }^{2}$ Universidade Federal de Viçosa, 36570-000, Viçosa, MG, Brasil

Autor para correspondência: Rodrigo Véras da Costa, e-mail: veras@cnpms.embrapa.br

\section{RESUMO}

Nos últimos anos, grande ênfase tem sido dada ao uso de fungicidas para o manejo de doenças foliares na cultura do milho no Brasil. Esse trabalho teve como objetivo a realização de uma análise da viabilidade técnica e econômica da aplicação de fungicidas no rendimento de cultivares de milho em diferentes regiões produtoras. Foram conduzidos experimentos para avaliação do efeito da aplicação de fungicidas no rendimento de diferentes cultivares de milho, em três localidades: Sete Lagoas (MG), Londrina (PR) e Rio Verde (GO). Foram consideradas a não aplicação, uma e duas aplicações de fungicidas em cada cultivar. Foram avaliadas a severidade das doenças foliares e o rendimento de cada cultivar. Os resultados de rendimento das cultivares tratadas com fungicidas apresentaram elevada inconsistência em condições de baixa severidade de doenças. Maior frequência de rendimentos positivos e benefício econômico ocorreu quando as aplicações de fungicida foram realizadas em condição de elevada pressão de doença. Mais estudos são necessários para o melhor entendimento do efeito dos fungicidas do grupo das estrobilurinas na fisiologia e na produção de plantas de milho.

Palavras-chave: Zea mays, azoxistrobina, efeito fisiológico, piraclostrobina.

\section{ABSTRACT}

Technical and economic feasibility of strobilurin fungicides application on maize

In recent years, great emphasis has been given to the use of fungicides for managing foliar diseases in corn in Brazil. This study aimed to conduct an analysis of technical and economic feasibility of application of fungicides on maize in different growing regions. Trials were conducted to evaluate the effect of fungicides on the yield of different maize cultivars at three locations: Sete Lagoas (state of Minas Gerais), Londrina (state of Paraná) and Rio Verde (state of Goiás). The effect of one and two fungicide applications on each cultivar was evaluated. For each trial, the difference in mean yield and disease severities between treated and untreated plots for each cultivars was compared. For all trials, yield response of cultivars treated with fungicides was highly inconsistent under low disease severity. A higher frequency of positive yields and economic benefit occurred when fungicide applications were made under conditions of high disease pressure. More studies are needed to better clarify the effect of strobilurin fungicides on the physiology and production of corn plants.

Key words: Zea mays, azoxystrobin, physiological effect, pyraclostrobin.

\section{INTRODUÇÃO}

A cultura do milho (Zea mays L.) está sujeita ao ataque de um grande número de patógenos que podem ocasionar perdas consideráveis em sua produtividade (Cunha et al., 2010; Juliatti et al., 2007). Tradicionalmente, o manejo das doenças do milho era realizado através da utilização de cultivares resistentes associados a medidas culturais. A partir da severa epidemia de cercosporiose (Cercospora zeae-maydis Tehon \& E.Y Daniels) ocorrida na região sudoeste do estado de Goiás, no ano de 2000, tem-se verificado um aumento acentuado da utilização de fungicidas em lavouras comerciais destinadas à produção de grãos.

Vários trabalhos têm demonstrado a eficiência dos fungicidas no manejo das doenças foliares e na redução dos danos por elas causadas na produtividade da cultura do milho (Cunha et al., 2010; Juliatti et al., 2007; Pinto et al., 2004 ). A partir do ano de 2000, uma nova classe de fungicida tornou-se disponível para produtores de milho, os inibidores de quinona oxidase $\left(\mathrm{Q}_{0} \mathrm{I}\right)$, conhecidos comumente como estrobilurinas. A toxicidade desses fungicidas advém da inibição da cadeia respiratória ao nível de complexo III, impedindo a cadeia bioquímica de transferência de elétrons no sítio da mitocôndria, interferindo na respiração dos fungos (Bartlett et al., 2002). Alguns fungicidas do grupo das estrobilurinas são reconhecidos por apresentarem um efeito de promoção do crescimento em certas espécies de plantas, os quais resultam em maior eficiência no uso de água e nitrogênio, retenção de clorofila, atraso na senescência foliar ("efeito verde"), aumento na atividade antioxidante e aumento de produtividade (Grossman \& Retzlaff, 1997; Ruske et al., 2003; Venâncio et al., 2003; Vincelli, 2002; Wu \& Tiedemann, 2002; Wu \& Tiedemann, 2001). A partir dessas 
observações, as empresas detentoras dessas moléculas têm divulgado o uso dos fungicidas estrobilurinas para o manejo de estresses bióticos e abióticos em diversas culturas, sugerindo um potencial aumento de produtividade mesmo na ausência de doenças no campo (Rava, 2002; Wise \& Mueller, 2011). Entretanto, os resultados de pesquisa têm demonstrado que os efeitos fisiológicos benéficos dos fungicidas do grupo das estrobilurinas são extremamente variáveis dependendo da cultura, da presença e severidade das doenças, da época de aplicação, dos produtos utilizados e das condições ambientais (Fagan et al., 2010; Scherm et al., 2009; Vincelli, 2002), apresentando, em alguns casos, efeitos negativos na produtividade (Below et al., 2009). Não se conhece, até o presente, resultados de pesquisa quantificando o potencial de aumento da produtividade da cultura do milho com aplicações de estrobilurinas na ausência de doenças, ou seja, quantificando o potencial benefício em produtividade oriundo unicamente do efeito fisiológico das estrobilurinas (Wise \& Mueller, 2011).

Uma análise econômica da resposta de cultivares de milho submetidas, ou não, à aplicação de fungicidas tem sido apresentada em alguns trabalhos de pesquisa realizados nos Estados Unidos (Paul et al., 2011; Wise \& Mueller, 2011). Verificou-se, nestes trabalhos, uma inconsistência do impacto dos tratamentos com estrobilurinas no rendimento das cultivares, quando se compararam áreas pulverizadas com fungicidas e áreas não pulverizadas. Fatores como o nível de resistência da cultivar, pressão de doenças, época de aplicação, sistema produtivo, fungicida utilizado e condições climáticas podem interferir no resultado da aplicação dos fungicidas no rendimento das cultivares de milho. Um entendimento melhor desses fatores é necessário antes da recomendação da aplicação destes fungicidas.

No Brasil, os resultados de pesquisa publicados se limitam à avaliação da eficiência dos fungicidas para o controle de doenças específicas e na produtividade das cultivares. Este trabalho teve como objetivo a realização de uma análise da viabilidade técnica e econômica da aplicação de fungicidas no rendimento de cultivares de milho em diferentes regiões produtoras.

\section{MATERIAL E MÉTODOS}

Foramconduzidosquatroexperimentosparaavaliação de uma e duas aplicações de dois fungicidas (comparandose com a não aplicação), em diferentes cultivares de milho, em condição de campo, em três localidades: Sete Lagoas (MG), Londrina (PR) e Rio Verde (GO). Em todos os experimentos as parcelas foram constituídas de quatro linhas de $5 \mathrm{~m}$, espaçadas de $0,8 \mathrm{~m}$, e com média de cinco plantas por metro. Os experimentos 1, 2 e 3 foram conduzidos em delineamento de blocos casualizados e arranjo fatorial (numero de aplicações x cultivar) com três repetições para cada tratamento. A adubação de semeadura consistiu da aplicação de $350 \mathrm{~kg} \mathrm{ha}^{-1}$ de NPK da formulação
8-28-16 + Zn. Aos 30 e 45 dias após a emergência (DAE) foram realizadas as adubações nitrogenadas em cobertura utilizando-se $150 \mathrm{~kg} \mathrm{ha}^{-1}$ de ureia. As aplicações de fungicida foram realizadas utilizando-se um pulverizador manual pressurizado a $\mathrm{CO}_{2}$, com vazão constante de $300 \mathrm{~L}$ ha $^{-1}$ e adição de óleo mineral na dose de $0,5 \%$ do volume de calda. As aplicações de fungicidas foram: 1) uma aplicação no estádio de 6 a 8 folhas; 2) duas aplicações, nos estádios de 6 a 8 folhas e no pré-pendoamento; e 3) sem aplicação de fungicidas.

Para as avaliações de produtividade, as espigas das plantas de duas linhas centrais (10 m lineares) de cada parcela foram colhidas, identificadas e pesadas (espigas e grãos) separadamente. O peso de grãos de cada parcela foi corrigido considerando $13 \%$ de umidade. A severidade das doenças foliares foi avaliada, aproximadamente, aos 100 DAE, utilizando-se uma escala de notas variando de $1(0 \%$ de severidade) a 5 (100\% das folhas com lesões, acima de $75 \%$ de severidade) (Agroceres, 1996).

\section{Experimento 1 - Sete Lagoas (MG) e Londrina (PR)}

$\mathrm{O}$ experimento foi conduzido em duas localidades: Sete Lagoas (MG), em área experimental da Embrapa Milho e Sorgo, e Londrina (PR), em área experimental da Embrapa Soja, na safrinha de 2008. As semeaduras foram realizadas em 28/02/2008, em Sete Lagoas, e em 19/02/2008, em Londrina. Foram utilizados 20 genótipos de milho, sendo um híbrido experimental e 19 cultivares comerciais. As cultivares foram submetidas às três condições de aplicação de fungicidas conforme descrito anteriormente. Foi utilizado o fungicida epoxiconazole + piraclostrobina, na dose de $0,75 \mathrm{~L} \mathrm{ha}^{-1}$.

\section{Experimentos 2 e 3 - Rio Verde (GO)}

Os experimentos $2 \mathrm{e} 3$ foram conduzidos no município de Rio Verde (GO), na safra 2009/2010, utilizando-se duas épocas de semeadura. As semeaduras foram realizadas em 21/10/2009 e 05/11/2009, para os experimentos 2 e 3, respectivamente. Os experimentos foram constituídos de 23 (experimento 2) e 26 (experimento 3 ) cultivares comerciais de milho. Foi utilizado o fungicida epoxiconazole + piraclostrobina, na dose de $0,75 \mathrm{~L} \mathrm{ha}^{-1}$.

\section{Experimento 4 - Sete Lagoas (MG)}

$\mathrm{O}$ experimento 4 foi conduzido na área experimental da Embrapa Milho e Sorgo, em Sete Lagoas (MG), no verão de 2010/2011, em uma área com histórico de ocorrência severa da mancha branca do milho causada por Pantoea anantis (Paccola-Meirelles et al., 2001; Casela \& Ferreira, 2006; Bomfeti et al., 2008; Lanza, 2009). A semeadura foi realizada em 18/11/2010. Foram utilizadas as cultivares Attack, Traktor e 30P70. As cultivares Attack e Traktor apresentam maior resistência à mancha branca e a cultivar 30P70 é considerada suscetível. Utilizou-se o delineamento experimental de blocos ao acaso, com 18 tratamentos dispostos em arranjo fatorial triplo (3 cultivares 
x 2 combinações de fungicidas x 3 aplicações) e três repetições. Foram utilizados os fungicidas epoxiconazole + piraclostrobina, na dose de $0,75 \mathrm{~L} \mathrm{ha}^{-1}$ e azoxistrobina + ciproconazole, na dose de $0,3 \mathrm{~L} \mathrm{ha}^{-1}$. As avaliações da severidade da mancha branca foram realizadas a partir do aparecimento dos primeiros sintomas das doenças nas folhas e continuadas em intervalo de, aproximadamente, 10 dias, sendo realizadas seis avaliações. Para tal, utilizou-se uma escala de notas variando de 1 ( $0 \%$ de severidade) a 5 (100\% das folhas com lesões, acima de 75\% de severidade) (Agroceres, 1996).

\section{Análise econômica e estatística}

A análise econômica, para os dados de produtividade, foi realizada em todos os experimentos conduzidos. Para tal, considerou-se a relação entre o rendimento de grãos, expressa em sacas ha-1 (uma saca $=60 \mathrm{~kg}$ ), das cultivares submetidas a uma e duas aplicações de fungicidas, em relação à testemunha sem aplicação. O custo total por hectare da aplicação de fungicidas foi considerado como a soma do custo médio dos fungicidas $(\mathrm{R} \$ 48,00)$ e o custo da aplicação terrestre $(\mathrm{R} \$ 23,00)$ e aérea $(\mathrm{R} \$ 37,00)$. No caso de apenas uma aplicação, o custo foi composto pelo preço médio dos fungicidas mais o custo da aplicação terrestre. Para duas aplicações o custo foi composto pelo preço médio dos fungicidas adicionado do custo das aplicações terrestre (primeira) e aérea (segunda). Os valores de custo para aplicação de fungicidas foram expressos em sacas $\mathrm{ha}^{-1}$, considerando-se o valor médio da saca de milho a $\mathrm{R} \$ 25,00$. O ganho produtivo para cada cultivar (rendimento) com uma ou duas aplicações de fungicidas foi comparado com o custo da aplicação utilizando o teste $\mathrm{t}(\mathrm{P}=0,05)$. Para os tratamentos com uma e duas aplicações o custo foi considerado 3 e 6,5 sacas ha- $^{-1}$, respectivamente.

Para o experimento 4, as notas de severidade da mancha branca obtidas em cada avaliação foram utilizadas para calcular a área abaixo da curva de progresso da doença (AACPD) (Shaner \& Finney, 1977). Os valores de AACPD de cada tratamento foram submetidos à análise de variância e as médias, quando necessário, foram comparadas entre si utilizando o teste de Tukey a 5\% de probabilidade.

\section{RESULTADOS}

Em todos os experimentos foi observado o mesmo padrão de resposta de produtividade dos diferentes cultivares à aplicação de fungicidas. $\mathrm{O}$ rendimento das cultivares submetidas à aplicação, em relação à testemunha sem fungicida, apresentou valores negativos, valores positivos abaixo dos limites dos custos de aplicação a valores positivos acima dos limites de custo. Os resultados demonstraram uma grande inconsistência de resposta de produtividade das cultivares à aplicação dos fungicidas. Algumas cultivares que apresentaram aumento de produtividade com uma aplicação, em relação ao tratamento sem fungicida, apresentaram resposta negativa com duas aplicações ou mesmo com uma aplicação em outra localidade (Figuras 1 e 2).

\section{Experimento 1}

No experimento conduzido em Sete Lagoas (MG), os valores de rendimento, em relação à testemunha, variaram de -33 a 30 sacas ha $^{-1}$. Com uma aplicação, 17 cultivares apresentaram aumento de produtividade, porém, quatro não diferiram do custo de aplicação (Figura 1). Com duas aplicações, sete cultivares apresentaram rendimentos negativos e 13 rendimentos positivos, no entanto, apenas oito obtiveram rendimento acima do custo de aplicação (Figura 2). As cultivares BRS3025, AS1570, DKB390, BRS1040 apresentaram resposta positiva com uma aplicação e resposta negativa com duas aplicações.

Para o mesmo experimento, conduzido em Londrina (PR), os valores de rendimento das cultivares, em relação à testemunha, variaram de -30 a 42 sacas ha ${ }^{-1}$. Neste experimento, cinco cultivares apresentaram resposta negativa de produtividade com uma aplicação de fungicida e nove cultivares apresentaram produtividade positiva superior ao custo de aplicação (Figura 1). Com duas aplicações, oito cultivares apresentaram resposta negativa e oito cultivares resposta positiva acima do custo de aplicação (Figura 2). Assim como para o experimento conduzido em Sete Lagoas, alguns cultivares (BRS1010, BRS1030, BRS1031, 2B710 e DKB390) apresentaram resposta positiva com uma aplicação e negativa com duas. As cultivares 3E5115 e 2B657 apresentaram resposta positiva com duas aplicações e negativa com uma.

Em Sete Lagoas, as principais doenças foliares detectadas nas avaliações foram a mancha branca, a mancha de Bipolaris (Bipolaris maydis (Nisikado) Shoemaker) e a antracnose foliar (Colletotrichum graminicola (Ces.) G. W. Wils.). Em Londrina, as principais doenças detectadas foram a mancha branca (P. ananatis), a ferrugem comum (Puccinia sorghi Schwein.) e a cercosporiose (C. zeae-maydis). Em ambos os locais, houve maior predominância da mancha branca, porém, as maiores severidades foram observadas em Sete Lagoas. As notas médias gerais para doenças foram de 3,9 e 3,0, para os experimentos conduzidos em Sete Lagoas e Londrina, respectivamente.

\section{Experimentos 2 e 3}

No experimento 2, conduzido em Rio Verde (GO), na primeira época de semeadura, os rendimentos das cultivares, em relação à testemunha, variaram de -19 a 34 sacas ha-1 ${ }^{-1}$ Neste experimento, considerando uma aplicação de fungicida, das 23 cultivares avaliadas, 11 apresentaram menor rendimento, quando comparadas às testemunhas sem aplicação (Figura 1). Onze cultivares apresentaram rendimento positivo maior que o custo de aplicação (Figura 1). Com duas aplicações, oito cultivares apresentaram resposta negativa e seis cultivares rendimento positivo e maior que o custo das aplicações (Figura 2). No experimento conduzido 

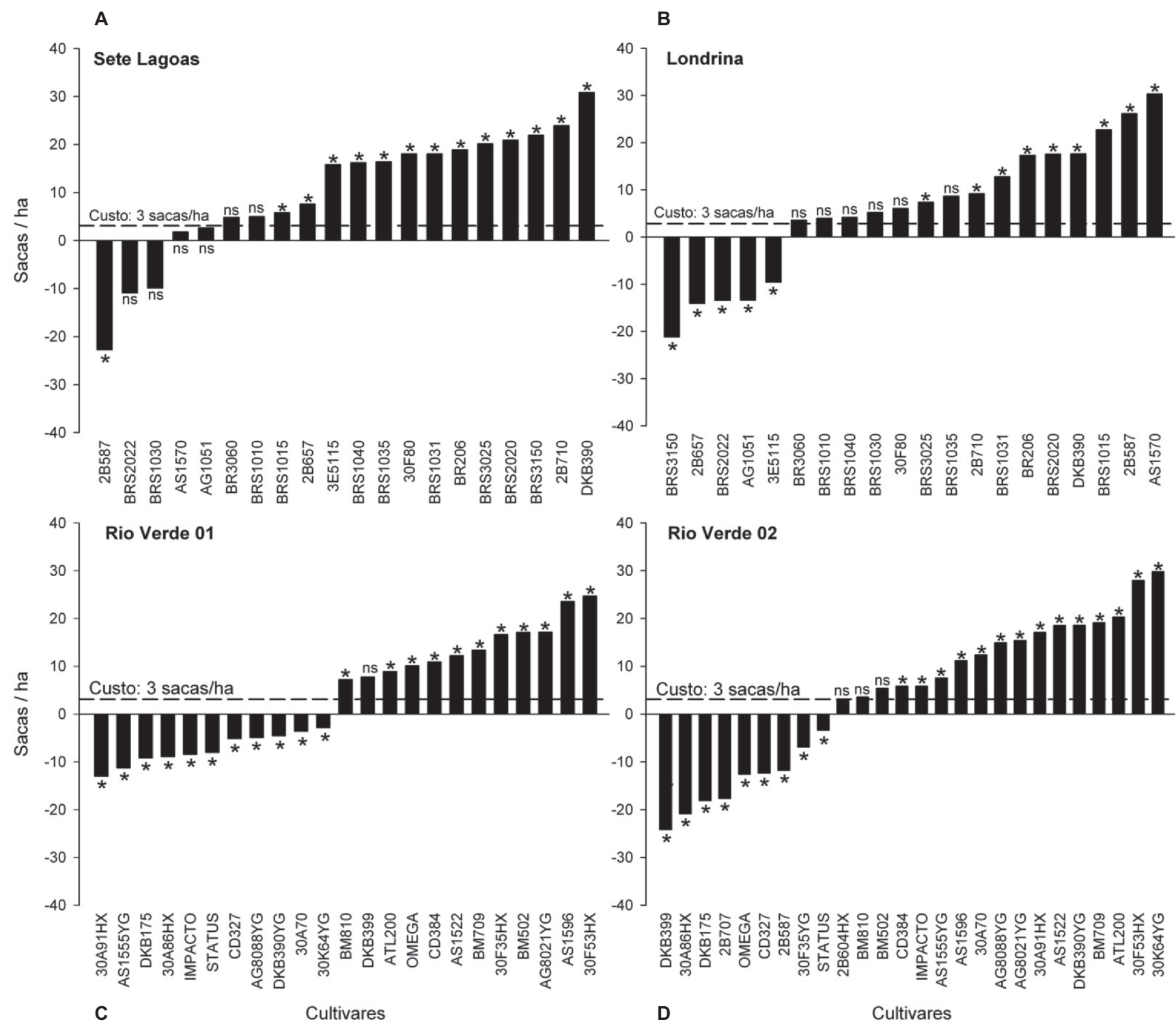

FIGURA 1 - Rendimento de cultivares de milho com uma aplicação de fungicidas, em relação à testemunha sem aplicação, em experimentos conduzidos em Sete Lagoas (MG) (A), Londrina (PR) (B) (safrinha de 2008) e em Rio Verde (GO) (C, D) (safra 2009/2010). A linha pontilhada representa o valor do custo estimado de uma aplicação do fungicida. *Híbridos cujo ganho ou perda na produção foi estatisticamente diferente do custo de aplicação (Teste t, $\mathrm{P}=0,05$ ); ns (não significativo): rendimento produtivo igual ao custo da aplicação.

em Rio Verde, na segunda época de semeadura (com 26 cultivares), o número de cultivares que apresentaram rendimento superior ao custo de aplicação foi maior que o verificado no experimento de primeira época (14 e 10 cultivares com uma ou duas aplicações, respectivamente). $\mathrm{Na}$ primeira época de semeadura, as cultivares AS1555YG, 30A86HX, 30A70 e 30K64YG apresentaram rendimento negativo com uma aplicação e positivo com duas (Figuras 1 e 2). No experimento conduzido na segunda época, as cultivares AS1555YG, 2B604Hx, Impacto, AS1596 e 30A70 apresentaram rendimento negativo com duas aplicações e rendimento positivo com uma aplicação. Os cultivares CD327, 30F35YG, STATUS, e DKB175 apresentaram rendimento positivo com duas aplicações e negativo com uma aplicação.

Em ambas as épocas de semeadura, as doenças detectadas foram: mancha branca, mancha foliar de Stenocarpela (Stenocarpella macrospora (Earle) Sutton), ferrugem polisora (Puccinia polysora Underw.), cercosporiose, mancha foliar de Turcicum (Exserohilum turcicum (Pass.) K.J. Leonard and E.G. Suggs) e antracnose foliar. No entanto, a intensidade das doenças variou entre as duas épocas de semeadura (os valores entre parênteses referem-se às notas médias de severidade das doenças na primeira e segunda época de semeadura, respectivamente): mancha branca $(2,0$ e 2,5$)$, mancha de foliar de stenocarpella 

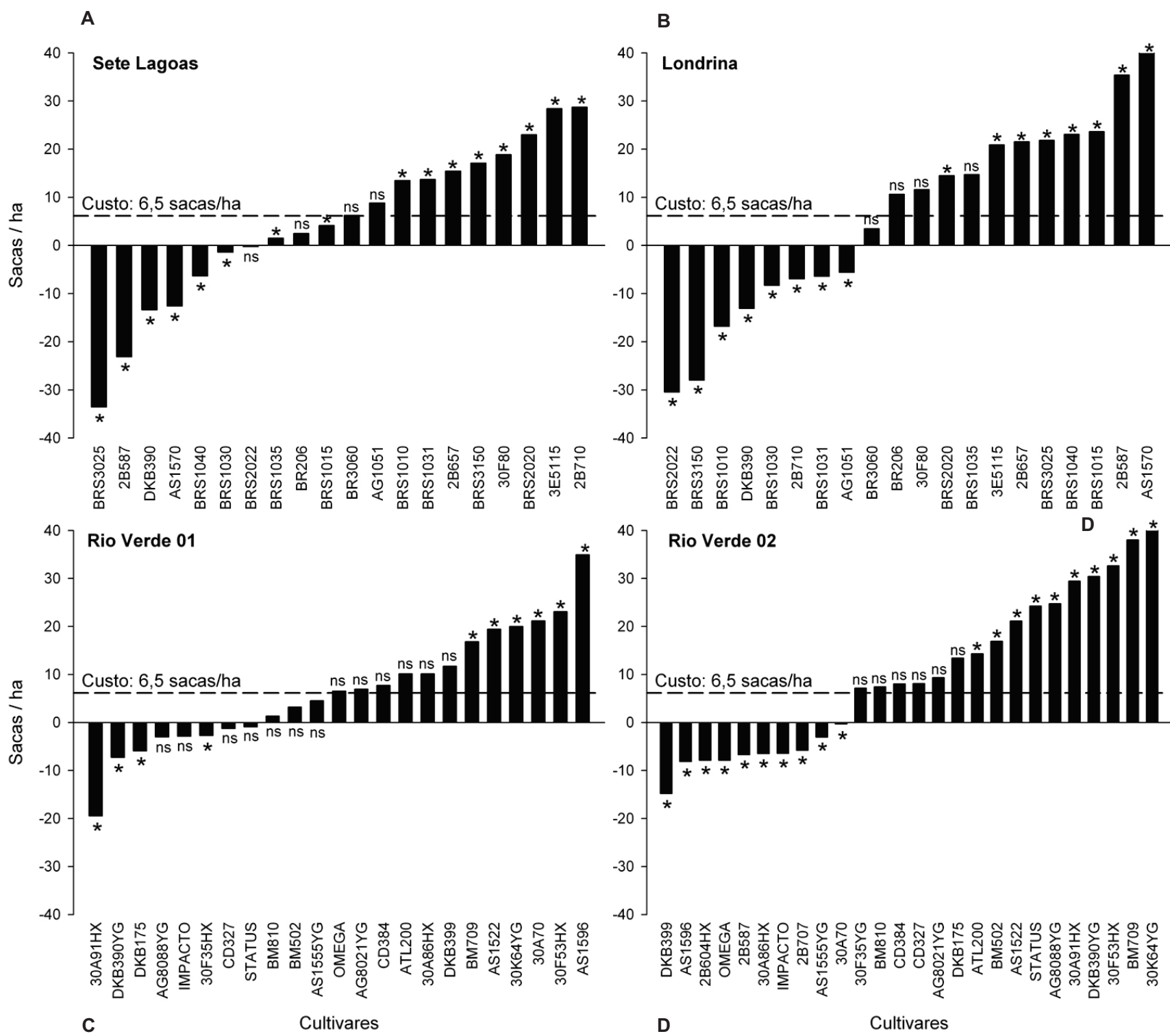

FIGURA 2 - Rendimento de cultivares de milho com duas aplicações de fungicidas, em relação à testemunha sem aplicação, em experimentos conduzidos em Sete Lagoas (MG) (A), Londrina (PR) (B) (safrinha de 2008) e em Rio Verde (GO) (C, D) (safra 2009/2010). A linha pontilhada representa o valor do custo estimado de duas aplicações de fungicida. *Híbridos cujo ganho ou perda na produção foi estatisticamente diferente do custo de aplicação (Teste t, $\mathrm{P}=0,05$ ); ns (não significativo): rendimento produtivo igual ao custo da aplicação.

(1,8 e 2,3$)$, ferrugem polissora $(1,1$ e 2,1$)$, cercosporiose $(1,1$ e 2,0$)$, mancha de turcicum $(1,0$ e 1,8$)$ e antracnose foliar $(1,6$ e 2,0$)$.

\section{Experimento 4}

Em Sete Lagoas (MG), durante o período de condução do experimento, foi verificada uma severa epidemia da mancha branca do milho, cuja nota final média de severidade no cultivar suscetível $30 \mathrm{P} 70$ foi 5,0 ( $100 \%$ das folhas com severidade superior a $75 \%)$. Para a variável AACPD detectou-se efeito significativo de híbrido $(\mathrm{P}<0,0001)$, fungicida $(\mathrm{P}<0,0001)$ e para a interação hibrido e fungicida $(\mathrm{P}<0,0001)$. O valor de AACPD foi significativamente superior na cultivar $30 \mathrm{P} 70 \mathrm{em}$ comparação às cultivares Attack e Traktor (Tabela 1). A utilização dos fungicidas epoxiconazole + piraclostrobina e azoxistrobina + ciproconazole foram eficientes em reduzir a severidade da doença, em comparação à testemunha. Não foi verificada diferença significativa na redução da AACPD nos tratamentos submetidos a uma e a duas aplicações $(\mathrm{P}=0,1433)$.

Os resultados de produtividade obtidos nesse experimento seguem o mesmo padrão descrito nos experimentos anteriores. $\mathrm{O}$ rendimento das cultivares 
TABELA 1 - Comparação dos valores de área abaixo da curva de progresso (AACPD) da mancha branca do milho para cultivares (Attack, Traktor e 30P70), fungicidas (epoxiconazole + piraclostrobina $0,75 \mathrm{~L} / \mathrm{ha}$, azoxistrobina + ciproconazole $0,3 \mathrm{~L} / \mathrm{ha}$ ) e testemunha (sem aplicação), em experimento conduzido em Sete Lagoas (MG)

\begin{tabular}{lccc}
\hline \hline Fungicida & \multicolumn{2}{c}{ Cultivar } \\
\cline { 2 - 4 } & $\mathbf{3 0 P 7 0}$ & Attack & Traktor \\
\hline epoxiconazole + piraclostrobina & $51,43 \mathrm{Aa}^{*}$ & $9,08 \mathrm{Ba}$ & $12,17 \mathrm{Ba}$ \\
ciproconazole + azoxistrobina & $81,40 \mathrm{Ab}$ & $24,67 \mathrm{Bab}$ & $19,00 \mathrm{Ba}$ \\
Testemunha & $363,33 \mathrm{Ac}$ & $54,00 \mathrm{~B} \mathrm{~b}$ & $83,67 \mathrm{Cb}$ \\
\hline
\end{tabular}

*Médias seguidas pela mesma letra minúscula na coluna e maiúscula na linha não diferem entre si pelo teste de Tukey $(\mathrm{P}=0,05)$

comparado à testemunha, sem aplicação, variou de -15 a 8 sacas ha $^{-1}$ com uma aplicação, e -15 a 20 sacas ha $^{-1}$, com duas aplicações de fungicidas (Figura 3). Os maiores rendimentos oriundos da aplicação dos fungicidas foram obtidos na cultivar suscetível à mancha branca, 30P70. Comparando-se uma aplicação com o tratamento sem aplicação, apenas a cultivar 30P70 apresentou rendimento acima do limite de custo de aplicação com o fungicida azoxistrobina + ciproconazole. A aplicação do fungida epoxiconazole + piraclostrobina resultou em aumento da produção, no entanto, o aumento não foi maior que o custo da aplicação (Figura 3). Comparando-se duas aplicações com o tratamento sem aplicação, apenas a cultivar 30P70 pulverizada com o produto epoxiconazole + piraclostrobina apresentou produtividade superior ao custo das aplicações (Figura 3).

\section{DISCUSSÃO}

Nos últimos anos, o uso de fungicidas foliares em lavouras comerciais de milho tem aumentado de forma significativa nas principais regiões produtoras do Brasil e no mundo (Adee et al., 2005; Cunha et al., 2010; Juliatti et al., 2007; Munkvold et al., 2001; Pinto et al., 2004; Shah \& Dillard, 2010). Tem sido bastante discutida e divulgada a existência de efeitos fisiológicos dos fungicidas do grupo das estrobilurinas em diversas culturas, inclusive no milho. Algumas empresas têm divulgado o uso desses fungicidas para o manejo de estresses bióticos e abióticos em diversas culturas, sugerindo um potencial aumento de produtividade mesmo na ausência de doenças no campo (Rava, 2002; Wise \& Mueller, 2011). No entanto, não se conhecem resultados de pesquisa quantificando esse potencial aumento da produtividade em milho advindo da utilização dos fungicidas estrobilurinas, e a magnitude dos benefícios econômicos desses fungicidas tem sido bastante questionada por parte de alguns patologistas de milho (Munkvold et al., 2001).

No presente estudo, os resultados obtidos demonstram elevada inconsistência de resposta de produtividade de cultivares de milho à aplicação de fungicidas. Essa inconsistência é observada como uma ausência de repetibilidade dos ganhos produtivos de diferentes cultivares quando submetidas à aplicação de fungicidas em comparação a parcelas não tratadas. Algumas cultivares apresentaram rendimento produtivo superior ao limite de custo quando submetidas a uma aplicação de fungicida, mas quando tratadas com duas aplicações o rendimento foi negativo, ou seja, produziram menos que a testemunha sem aplicação. Em outras situações, a mesma cultivar apresentou aumento de produtividade superior ao custo de aplicação em determinada localidade, e inferior em outro local, considerando o mesmo número de aplicações e o produto utilizado. Esses resultados estão de acordo com os obtidos por Wise \& Mueller (2011) nos Estados Unidos. Segundo os autores, em 472 tratamentos em que se compararam áreas tratadas e não tratadas com fungicidas, $80 \%$ apresentaram resposta de produtividade positiva a uma aplicação de fungicida e, em $20 \%$ dos casos, foi obtida resposta de produtividade nula ou negativa à aplicação. Em outro estudo, a resposta de redução de produtividade em relação à testemunha foi obtida em 26 a 48\% dos casos, dependendo do fungicida utilizado (Paul et al., 2011). Resultados semelhantes foram obtidos em outros estudos (Khan \& Carlson, 2009; Nason, et al., 2007; Nelson et al., 2010; Swoboda \& Pedersen, 2009).

A aplicação de fungicida resultou em aumento de produtividade em várias cultivares de milho em todos os experimentos conduzidos no presente estudo. No entanto, em diversas situações, esses aumentos não resultaram em benefício econômico, ou seja, o aumento de produtividade foi menor que o custo requerido para a realização da aplicação do fungicida. Resultados semelhantes têm sido observados em outros trabalhos (Paul et al., 2011; Wise \& Mueller, 2011). A obtenção de benefício econômico positivo da aplicação de fungicida não depende apenas do aumento de produtividade obtido, mas, também, do custo necessário para a aplicação do fungicida e do preço de mercado da saca de milho. Esses fatores podem apresentar variação de região para região e ao longo do tempo de acordo com as oscilações de mercado.

De modo geral, menor inconsistência na resposta de produtividade das cultivares e maior benefício econômico da aplicação de fungicida, dado pelo número de 

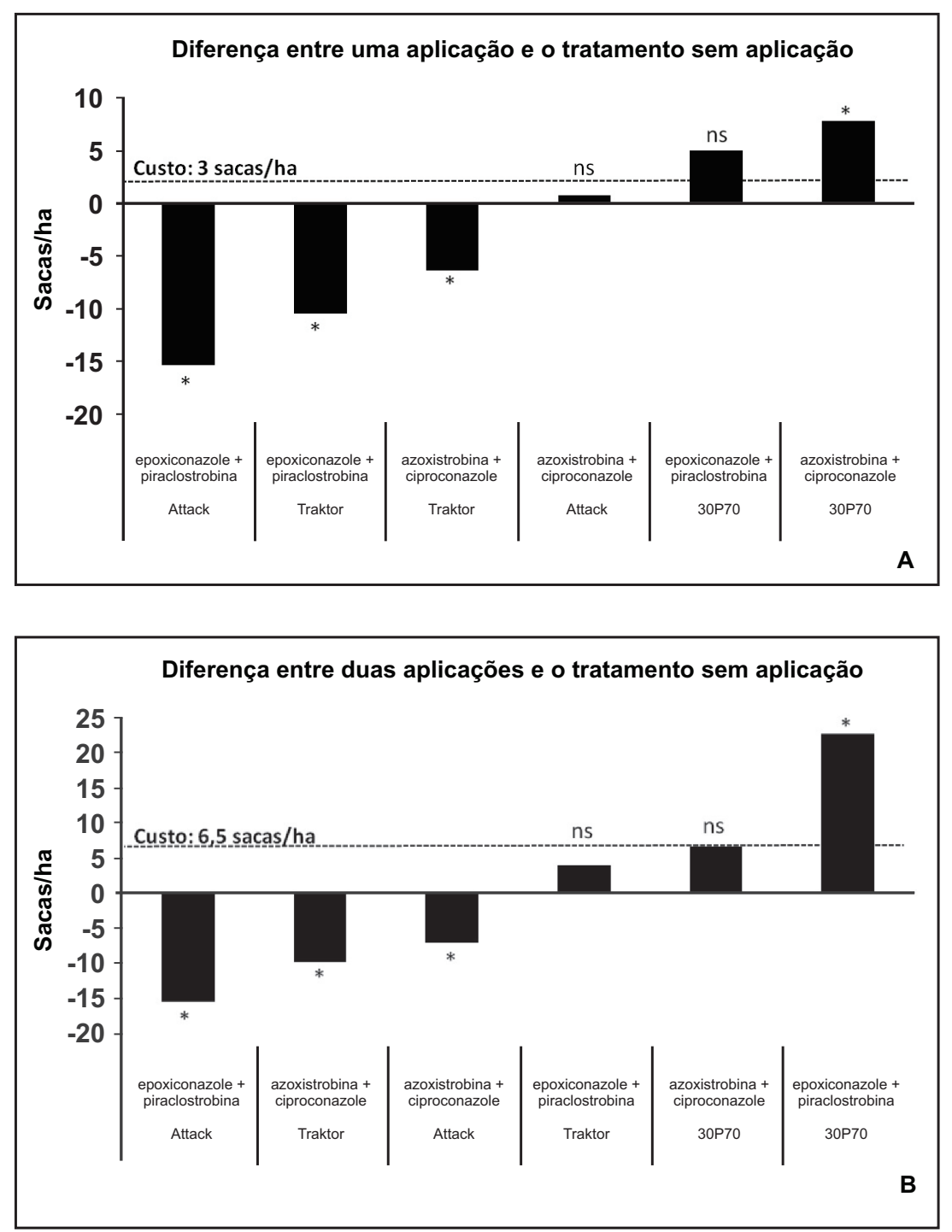

FIGURA3 - Rendimento de cultivares de milho comparando-se uma (A) e duas aplicações (B) em relação à testemunha sem aplicação, em experimentos conduzidos em Sete Lagoas (MG), safra 2010/2011. A linha pontilhada representa o valor do custo da aplicação do fungicida em sacas/ha. *Híbridos cujo ganho ou perda produção foi estatisticamente diferente do custo de aplicação (Teste t, $\mathrm{P}=0,05$ ); ns (não significativo): rendimento igual ao custo da aplicação. cultivares com rendimento superior ao custo de aplicação, ocorreram nas situações em que foram registradas as maiores severidades das doenças. Os maiores rendimentos produtivos e as menores inconsistências de resposta à aplicação de fungicidas ocorrem em situações de elevada pressão de doença, que normalmente são resultantes do uso de cultivares suscetíveis em locais com condições favoráveis ao desenvolvimento das doenças e com elevado potencial de inóculo na área. Esses resultados estão de acordo com os obtidos por Paul et al. (2011). Esses autores utilizaram resultados de experimentos de aplicação foliar de fungicidas conduzidos entre os anos de 2002 a 2009 , em quatro estados dos Estados Unidos, para determinar a resposta de produtividade do milho à aplicação de diferentes fungicidas contendo estrobilurinas nas misturas. Segundo os autores, é improvável a obtenção de benefício econômico da aplicação foliar de fungicidas na cultura do milho quando a severidade das doenças foliares é baixa e a expectativa de produtividade é alta. Wise \& Mueller (2011), em experimentos de aplicação de fungicida em milho em diferentes regiões entre os anos de 2005 a 2009, verificaram que no estado de Nebraska, onde a pressão de doença é, normalmente, maior, em $90 \%$ dos tratamentos submetidos à aplicação de fungicida o rendimento foi superior ao custo de aplicação. Por outro lado, em locais onde a pressão de doença é baixa, os resultados de aumentos de produtividade foram inconsistentes, quando se compararam tratamentos com e sem aplicação de fungicidas.

No presente trabalho, a obtenção de rendimento positivo acima do custo de aplicação foi verificada em um maior número de cultivares quando realizada uma aplicação de fungicida. A obtenção de benefício econômico com duas aplicações de fungicida depende, provavelmente, do nível de doença e da expectativa de produtividade a ser alcançada. Quanto maior a pressão de doença nas fases da cultura posteriores à polinização, maior será o retorno econômico 
da segunda aplicação. No entanto, se a expectativa de produção for similar àquela obtida com uma aplicação, a probabilidade de retorno econômico da segunda aplicação é menor. Munkvold et al. (2001), utilizando análises de inferência bayesiana para calcular a probabilidade de retorno líquido positivo com uma ou duas aplicações de fungicidas em 10 experimentos de campo, considerando parcelas tratadas e não tratadas, o preço dos grãos e o custo das aplicações, concluíram que a probabilidade de retorno positivo líquido foi quase sempre maior com uma aplicação de fungicida (acima de 50\% em seis dos nove experimentos); verificaram também que essa probabilidade é fortemente influenciada pela suscetibilidade do híbrido. Segundo os autores, híbridos resistentes são menos responsivos ao tratamento com fungicida que híbridos suscetíveis. Resultados semelhantes foram obtidos por Paul et al. (2011).

Outro fator que chama a atenção nos resultados obtidos nesse trabalho e nos resultados obtidos por Paul et al. (2011) e Wise \& Muller (2011) é a elevada ocorrência de resultados negativos de rendimento, ou seja, quando a produtividade é menor em áreas tratadas com fungicidas em relação a áreas não tratadas. Esse aspecto não tem sido discutido nos trabalhos acima citados. Considerando que os fungicidas do grupo das estrobilurinas podem interferir na fisiologia das plantas de milho, uma questão a ser respondida seria: poderiam esses fungicidas interferir na fisiologia da planta de milho de maneira prejudicial, resultando em redução na produtividade da cultura? Um estudo interessante foi desenvolvido por Below et al. (2009). Segundo os autores, os fungicidas do grupo das estrobilurinas atuam inibindo a atividade da enzima ACC sintase, enzima chave na síntese de etileno na planta, um hormônio responsável pelo desenvolvimento das espigas. Portanto, a aplicação de fungicidas no milho entre os estádios V11 e V15 atuaria na redução dos níveis de etileno nas plantas resultando em uma intensificação da ocorrência de espigas mal formadas, com consequentes perdas na produtividade. As aplicações de estrobilurina resultaram em 41,2 e $51 \%$ de espigas mal formadas quando realizadas nos estádios V11 e V15, respectivamente, contra 0,1 e $1,2 \%$ na testemunha sem aplicação. Além desse efeito na síntese de etileno, as estrobilurinas podem atuar em outros processos metabólicos na planta de milho, como a fotossíntese e a degradação de clorofila (Grossman \& Retzlaff, 1997). Segundo Below et al. (2009), não se pode descartar a possibilidade de as estrobilurinas interferirem em outros processos regulatórios nas plantas que afetem a produtividade da cultura sob determinadas situações de ambiente, e que, adjuvantes utilizados nas misturas com fungicidas também possam afetar a síntese de etileno na planta e, consequentemente, o desenvolvimento normal das espigas. Nesse contexto, vale ressaltar que, nos Estados Unidos, a bula dos produtos Quilt (azoxistrobina + propiconazole) e Quilt Exel (azoxistrobina + propiconazole) registrados para o manejo de doenças na cultura do milho, traz uma ressalva de que a aplicação desse produto, antes da fase do pendoamento, pode impor estresses nas plantas que podem inibir o desenvolvimento normal dos grãos, especialmente em condições de estresses ambientais (Syngenta Crop Protection, 2011).

Conclui-se, portanto, que os resultados de rendimento nas cultivares tratadas com fungicidas apresentaram elevada inconsistência em condições de baixa severidade de doenças. Portanto, é necessário cautela na recomendação de fungicidas, principalmente se há baixa expectativa de produtividade. Maior frequência de rendimento positivo e de benefício econômico ocorreu quando as aplicações de fungicida foram realizadas em condição de elevada pressão de doença. Recomenda-se a aplicação de fungicidas para cultivares suscetíveis em condições favoráveis ao desenvolvimento de doenças, no que se refere ao clima e ao sistema de produção, condições em que foram observadas as menores inconsistências de produtividade e maior custo benefício da aplicação. Mais estudos são necessários para o melhor entendimento do efeito das estrobilurinas na fisiologia e seus reflexos sobre a produtividade de plantas de milho.

\section{REFERÊNCIAS BIBLIOGRÁFICAS}

Adee EA, Paul LE, Nafziger ED, Bollero G (2005) Yield loss of corn hybrids to incremental defoliation. Crop Management, DOI:10.1094/CM-2005-0427-01-RS.

Agroceres (1996). Guia Agroceres de Sanidade. 2. ed. São Paulo SP. Brasil. Sementes Agroceres.

Bartlett DW, Clough JM, Godwin JR, Hall AA, Hamer M, ParrDobrzanski B (2002) The strobilurin fungicides. Pest Management Science 58:649-662.

Below FE, Duncan KA, Uribelarrea M, Ruyle TB (2009) Occurrence and proposed cause of hollow husk in maize. Agronomy Journal 101:237-242.

Bonfeti CA, Souza-Paccola EA, Massola Junior NS, Marriel IE, Meirelles WF, Casela CR, Paccola-Meirelles LD (2008) Localization of Pantoea ananatis inside lesions of maize white spot diseases using transmission electron microscopy and molecular techniques. Tropical Plant Pathology 33:63-66.

Casela CR, Ferreira AS (2006). The phaeosphaeria leaf spot of maize in Brazil: evidence of a new etiological agent? Fitopatologia Brasileira 31:335-336.

Cunha JPAR, Silva LL, Boller W, Rodrigues JF (2010) Aplicação aérea e terrestre de fungicida para o controle de doenças do milho. Ciência Agronômica 41:366-372.

Fagan EB, Neto DD, Vivian R, Franco RB, Yeda MP, Massignam LF, Oliveira RF, Martins KV (2010) Efeito da aplicação de piraclostrobina na taxa fotossintética, respiração, atividade da enzima nitrato redutase e produtividade de grãos de soja. Bragantia 69:771-777.

Grossman K, Retzlaff G (1997) Bioregulatory effects of the fungicide strobilurin kresoxim-methyl in wheat (Triticum aestivum). Pesticide Science 50:11-20.

Juliatti FC, Zuza JLMF, Souza PP, Polizel AC (2007) Efeito do 
genótipo de milho e da aplicação foliar de fungicidas na incidência de grãos ardidos. Bioscience Journal 23:34-41.

Khan MFR, Carlson AL (2009) Effect of fungicides on sugar beet yield, quality, and postharvest respiration rates in the absence of disease. Plant Health Progress, DOI:10.1094/PHP-2009-1019-01RS.

Lanza FE (2009) Mancha branca do milho: etiologia e resistência de genótipos. Dissertação de Mestrado, Universidade Federal de Viçosa. Viçosa MG, Brasil.

Munkvold GP, Martinson, CA, Shriver JM, Dixon PM (2001) Probabilities for profitable fungicide use against gray leaf spot in hybrid maize. Phytopathology 91:477-484.

Nason MA, Farrar J, Bartlett D (2007) Strobilurin fungicides induce changes in photosynthetic gas exchange that do not improve water use efficiency of plants grown under conditions of water stress. Pest Management Science 63:1191-1200.

Nelson KA, Motavalli PP, Stevens WE, Dunn D, Meinhardt CG (2010) Soybean response to preplant and foliar-applied potassium chloride with strobilurin fungicides. Agronomy Journal 102:16571663.

Paccola-Meirelles LD, Ferreira AS, Meirelles WF, Marriel IE, Casela CR (2001) Detection of a bacterium associated with a leaf spot disease of maize in Brazil. Journal of Phytophathology 149:275-279.

Paul PA, Madden LV, Bradley CA, Robertson A, Munkvold G, Shaner G, Wise K, Malvick D, Allen TW, Grybauskas A, Vincelli P, Esker P (2011) Meta-analysis of yield response of hybrid field corn to foliar fungicides in the U.S. corn belt. Phytopathology 101:1122-1132.

Pinto NFJA (2004) Controle químico de doenças foliares em milho. Revista Brasileira de Milho e Sorgo 3:134-138.

Rava CA (2002) Eficiência de fungicidas no controle da antracnose e mancha angular do feijoeiro comum. Summa Phytopathologica 28:65-69.
Ruske RE, Gooding MJ, Jones SA (2003) The effects of triazole and strobilurin fungicide programmes on nitrogen uptake, partitioning, remobilization and grain $\mathrm{N}$ accumulation in winter wheat cultivars. Journal of Agricultural Science 140:395-407.

Shah DA, Dillard HR (2010) Managing foliar diseases of processing sweet 10 corn in New York with strobilurin fungicides. Plant Disease 94:213-220.

Scherm H, Chistiano RSC, Esker PD, Del Ponte EM, Godoy CV (2009) Quantitative review of fungicide efficacy trials for managing soybean rust in Brazil. Crop Protection 28:774-782.

Shaner G, Finney RE (1977) The effect of nitrogen fertilization on the expression of slow-mildewing resistance in knox wheat. Phytopathology 67:1051-1056.

Syngenta Crop Protection (2011) Fungicide Quilt Xcel. Available at: http:/www.syngentacropprotection.com/pdf/labels/ SCP1324AL10309.pdf. Accessed on July 10, 2011.

Swoboda C, Pedersen P (2009) Effect of fungicide on soybean growth and yield. Agronomy Journal 101:352-356.

Venâncio WS, Rodrigues MAT, Begliomini E, Souza N (2003) Physiological effects of strobilurin fungicides on plants. Publication UEPG 9:59-68.

Vincelli P (2002) $Q_{0}$ I (strobilurin) fungicides: benefits and risks. Plant Health Instructor, DOI: 10.1094/PHI-I-2002-0809-02.

Wise K, Mueller D (2011) Are fungicides no longer just for fungi? An analysis of foliar fungicide use in corn. APSnet Features, DOI:10.1094/APSnetFeature-2011-0531.

Wu Y, Von Tiedemann A (2002) Impact of fungicides on active oxygen species and antioxidant enzymes in spring barley (Hordeum vulgare L.) exposed to ozone. Environmental Pollution 116:37-47.

Wu Y, Von Tiedemann A (2001) Physiological effect of azoxystrobin and epoxiconazole on senescence and the oxidative status of wheat. Pesticide Biochemistry and Physiology 71:1-10. 